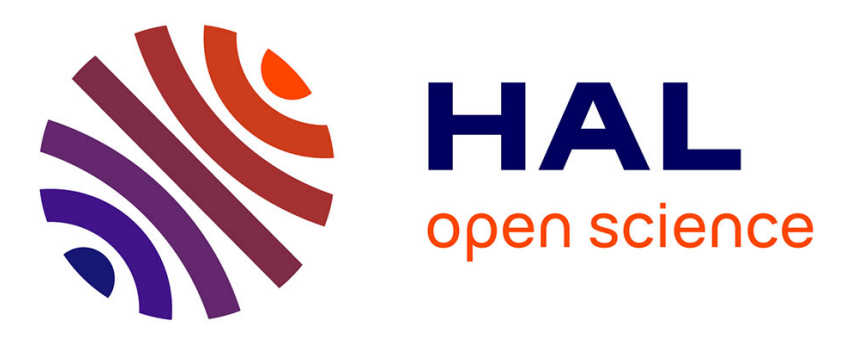

\title{
Reconstruction of Heat Sources Induced in Superelastically Loaded Ni-Ti Wire By Localized Deformation Processes
}

\author{
A. Jury, Xavier Balandraud, L. Heller, P. Šittner, M. Karlik
}

\section{- To cite this version:}

A. Jury, Xavier Balandraud, L. Heller, P. Šittner, M. Karlik. Reconstruction of Heat Sources Induced in Superelastically Loaded Ni-Ti Wire By Localized Deformation Processes. Experimental Mechanics, 2021, 61 (2), pp.349-366. 10.1007/s11340-020-00648-8 . hal-03184833

\section{HAL Id: hal-03184833 \\ https://hal.science/hal-03184833}

Submitted on 29 Mar 2021

HAL is a multi-disciplinary open access archive for the deposit and dissemination of scientific research documents, whether they are published or not. The documents may come from teaching and research institutions in France or abroad, or from public or private research centers.
L'archive ouverte pluridisciplinaire HAL, est destinée au dépôt et à la diffusion de documents scientifiques de niveau recherche, publiés ou non, émanant des établissements d'enseignement et de recherche français ou étrangers, des laboratoires publics ou privés. 


\section{Reconstruction of heat sources induced in superelastically loaded Ni-Ti wire by localized deformation processes}

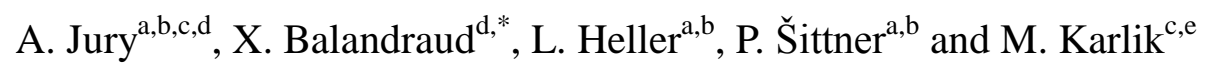

${ }^{a}$ Nuclear Physics Institute of the CAS, Husinec, Rež 130, 250 68, Rež, Czech Republic

${ }^{b}$ Institute of Physics of the CAS, Na Slovance 1992/2, 18221 Prague, Czech Republic

${ }^{c}$ Czech Technical University in Prague, Faculty of Nuclear Sciences and Physical

Engineering, Department of Materials, Trojanova 13, 12000 Prague 2, Czech Republic

${ }^{\mathrm{d}}$ Université Clermont Auvergne, CNRS, SIGMA Clermont, Institut Pascal, F-63000

Clermont-Ferrand, France

${ }^{\mathrm{e}}$ Charles University, Faculty of Mathematics and Physics, Department of Physics of

Materials, Ke Karlovu 5, 12116 Prague 2, Czech Republic

* Corresponding author at: Université Clermont Auvergne, CNRS, SIGMA Clermont, Institut

Pascal, Campus Universitaire des Cézeaux, F-63000 Clermont-Ferrand, France.

Tel.: +33473288089.

Fax: +33473288 100 .

E-mail address: xavier.balandraud@sigma-clermont.fr (X. Balandraud). 


\section{Abstract}

Background: Shape memory alloys (SMAs) are phase transforming materials featuring strong thermomechanical couplings. Infrared thermography and heat source reconstruction (HSR) enable to track the calorific signature of deformation processes. Objective: The objective was to characterize the transformation processes in a superelastic nickel-titanium SMA wire subjected to a force-controlled superelastic tensile cycle. Methods: In-situ recorded thermographs were converted into spatiotemporal maps of heat sources using an inhouse developed post-processing method based on the heat diffusion equation resolved numerically for unknown heat sources. Results: Sequentially appearing patterns of localized transformation events of four types were identified and associated with martensite bands nucleations and their subsequent merging upon tensile loading. Analogically, the events associated with austenite bands nucleations and their subsequent merging were identified upon unloading. In addition, weak heat sources observed before and after the localized transformation events were associated with the homogeneous martensitic transformation. Conclusions: The intrinsic dissipation heat associated with the nucleation and merging events is estimated to be $\sim 25 \%$ of the released/absorbed latent heat.

\section{Keywords}

Infrared thermography; Heat effect; Material characterization; Shape memory alloy; Superelasticity; Thermal diffusivity 


\section{Introduction}

Shape memory alloys (SMAs) are smart materials that exhibit several attractive thermomechanical properties such as shape memory effects, superelasticity and high damping capacity [1-3]. These macroscopic properties originate from a diffusionless solid-solid phase transition that is induced thermally or mechanically. Near-equiatomic nickel-titanium (NiTi) alloys, and more generally NiTi-based SMAs, are the most frequently selected in engineering applications. Moreover, good resistance to corrosion and fatigue makes these alloys excellent candidates to biomedical applications $[4,5]$. For polycrystalline specimens, the tensile response generally exhibits the nucleation and propagation of phase transformation bands with transformation fronts separating the two phases involved, namely austenite (A) and martensite (M). Occurrence and features of transformation fronts in specimens depend on the manufacturing process (cold working, heat treatment), specimen geometry, environmental conditions of the test (ambient temperature and thermal exchange conditions) and loading conditions (stress level and loading rate). These phase transformation fronts have been extensively studied in the literature. They were described first in NiTi in Ref. [6] and then investigated in many studies (see for instance Refs [7, 8]). The reader may refer to Ref. [9] for details on the origin of these fronts, which are also known as Lüders-like deformation bands. The present study is dedicated to a full-field infrared (IR) measurement technique aiming at characterizing the spatio-temporal calorific signature of phase transformation bands and their fronts propagating in a NiTi-based SMA wire superelastically loaded at relatively high strain rates in tension under quasi-adiabatic conditions. The nucleating and spreading phase transformation bands give rise to multiple heat bursts that lead to complex spatio-temporal temperature pattern being very challenging for heat source reconstruction (HSR). We selected this problem of strong thermomechanical coupling in mechanics of materials for two reasons. First for its scientific relevance as such loading conditions are expected in some applications 
such as shock dampers [10]; secondly to show how the HSR method presented in this paper is robust.

Phase transformation fronts in SMAs are classically tracked in-situ by using optical images and digital image correlation (DIC) to measure sudden local changes in strain or strain rates, see for instance Ref. [11]. IR thermography is an alternative way to evidence phase transition in these alloys, see for instance Refs [12-24]. Indeed, the $A \rightarrow M$ (forward) and $M \rightarrow A$ (reverse) transformations are accompanied by latent heat release and absorption, respectively. Basically, in the context of mechanics of materials, IR thermography enables the measurement of temperature changes at the surface of a material sample subjected to mechanical loading. The present study focuses on the quantification of the heat sources related to stress-induced martensitic transformation inducing the temperature changes recorded by IR thermography. By heat source, we mean the heat power density (in W.m ${ }^{-3}$ ) released or absorbed by the material itself, i.e., due to changes in its physical state and not due to heat conduction, convection or radiation. HSR is based on the heat diffusion equation, where individual terms are evaluated from measured time-resolved temperature fields [23-27]. This approach has not yet been fully developed and used as opposed to other full-field measurement techniques in mechanics of materials such as DIC or TSA (thermoelastic stress analysis). Moreover, HSR has been rarely applied to NiTi-based SMAs. Some applications concern tubes $[28,29]$. A macroscopic approach was developed for tension-compression in Ref. [30] and for shear in Ref. [31]. Attention was paid to the energy balance in tension during a load-unload cycle in Ref. [32]. To the best knowledge of the authors, one-dimensional (1D) HSR has never been applied to superelastic NiTi-based SMA wires loaded in tension.

Let us recall that the stress-strain curve of superelastic NiTi-based wires generally features a "stress plateau" in the case of a quasi-static displacement-controlled test [7, 8, 33-38]. In such 
a case, the phase transformation occurs within the one or more transformation band fronts propagating at a constant force. On the contrary, multiple bands are expected for forcecontrolled loadings [13, 20, 38]. Indeed, rapid local release or absorption of phase transformation latent heat leads to a strongly heterogeneous temperature distribution along the wire. As phase transition is driven by both stress and temperature, complex thermomechanical coupling thus occurs for force-controlled tests leading to the occurrence of multiple bands. 1D HSR was applied in the present study to characterize such complex kinetics of phase transformation. The objective is to evidence and quantify the calorific signature of the forward and reverse phase transition, both in time and in space along the wire, proceeding at relatively high load rates during a force-controlled loading-unloading cycle.

\section{Heat source reconstruction - the background}

Generally, the thermomechanics of materials (extensively detailed in Ref. [39]) distinguishes between two different groups of internal heat source origins as follows:

- intrinsic dissipation $\left(d_{1}>0\right)$ due to any irreversible mechanical phenomena such as viscosity, plasticity, dislocations, cracks or fatigue damage. It is to be distinguished from the thermal dissipation $d_{2}$, both terms being involved in the Clausius-Duhem inequality $d_{1}+d_{2}>0$

- thermomechanical couplings $\left(s_{\mathrm{th}-\mathrm{mec}}\right)$ involving thermoelastic contribution $\left(s_{\mathrm{th}-\mathrm{el}}\right)$ present in all materials: $s_{\text {th-el }}$ is negative when stress increases and positive when stress decreases. In SMAs, a latent heat term $\left(s_{\text {transf }}\right)$ is also involved: it is positive when $\mathrm{A} \rightarrow \mathrm{M}$ transformation occurs, and negative for the reverse transformation. 
Internal heat source appears through the total term $s_{\text {int }}=d_{1}+s_{\text {th-mec }}$, i.e. $s_{\text {int }}=d_{1}+$ $s_{\text {th-el }}+s_{\text {transf }}$, in the right-hand side of the heat diffusion equation as follows:

$$
\rho C \frac{d T}{d t}-\operatorname{div}(k \operatorname{grad} T)=s_{\mathrm{ext}}+s_{\mathrm{int}}
$$

where $\rho$ is the density $\left(\mathrm{kg} \cdot \mathrm{m}^{-3}\right), C$ the specific heat $\left(\mathrm{J}^{\mathrm{kg}} \mathrm{kg}^{-1} \cdot \mathrm{K}^{-1}\right), k$ the thermal conductivity $\left(\mathrm{W} \cdot \mathrm{m}^{-1} \cdot \mathrm{K}^{-1}\right), T$ the temperature $(\mathrm{K})$ and $s_{\text {ext }}$ the power density of heat-induced by external field sources such as Joule heating induced by applied electrical field (W. $\left.\mathrm{m}^{-3}\right)$. This equation can be reduced to a $1 \mathrm{D}$ version in the case of long thin specimens [23, 24, 26, 39-46]. It can be written in the following form after division by $\rho C$ and considering that $s_{\text {ext }}$ does not vary in time during the temperature measurement:

$$
\frac{\partial \Theta}{\partial t}+\frac{\Theta}{\tau_{1 \mathrm{D}}(\Theta)}-D \frac{\partial^{2} \Theta}{\partial z^{2}}=s
$$

where $\Theta$ is the temperature change with respect to the equilibrium state, $\tau_{1 \mathrm{D}}$ the characteristic time (s) for heat exchange between the specimen and ambient air, $D$ the thermal diffusivity $\left(\mathrm{m} . \mathrm{s}^{-2}\right.$ ) along longitudinal direction $z$, and $s$ the internal heat source here expressed in $\mathrm{K} . \mathrm{s}^{-1}$ $\left(s=s_{\text {int }} / \rho C\right)$. This later quantity is simply named "heat sources" in the following, whatever the sign of $s$ (positive for a heat production or negative for a heat absorption). Note that:

- $\Theta$ is a function of time $t$ and space $z$. An equilibrium state is defined in practice as the steady temperature field captured by the IR camera just before the beginning of mechanical loading. Thus $\Theta(z, t)=T(z, t)-T(z, 0)$;

- $\tau_{1 \mathrm{D}}$ is here assumed to be potentially dependent on temperature change $\Theta$, see Section "Heat exchange between the specimen and its surroundings" for its identification. For small temperature changes (a few $\mathrm{K}$ ), it is usually considered as a constant and sometimes named $\tau_{\mathrm{th}}^{1 \mathrm{D}}$ in the literature [24, 26, 39-46];

- thermal diffusivity is generally different for austenite and martensite. The superelastic SMA wire in the present study is entirely in the austenite phase at the beginning of the 
test at zero stress, i.e. $D(z, 0)=D_{\text {aust }}$, and progressively transforms to martensite upon loading.

A further simplification of the heat diffusion equation can be applied in the case of homogeneous heat source fields at the considered spatial resolution, i.e. when $s(z, t)=s(t)$. It is worth nothing that this equality does not imply the homogeneity of the thermal profiles. The latter are generally heterogeneous because of the contact with metallic jaws and depend on the thermal history of the specimen along with the mechanical test. A so-called zerodimensional (0D) version of the heat equation can then be used (see Refs [39, 47-49] and references included):

$$
\frac{d \Theta_{0 \mathrm{D}}}{d t}+\frac{\Theta_{0 \mathrm{D}}}{\tau_{0 \mathrm{D}}\left(\Theta_{\mathrm{OD}}\right)}=s
$$

where $\Theta_{0 D}$ is the average temperature change over the specimen gauge length. The term $\tau_{0 \mathrm{D}}\left(\Theta_{0 \mathrm{D}}\right)$ here is the characteristic time for heat exchange between the specimen and its entire environment, i.e. ambient air and jaws of the testing machine. For small temperature changes (a few $\mathrm{K}$ ), it is usually considered as a constant and named $\tau$ or $\tau_{\text {eq }}$ in the literature.

HSR can be performed by evaluating the heat source $s$ by direct calculation of the left-hand side of Equations (2) or (3). The strength of the approach is in fast numerical evaluation of heat sources without knowing the theoretical thermal solution. The difficulty is that experimental data are unavoidably noisy, which is strongly penalizing for the calculation of the derivative terms. Different approaches have been developed in the literature for filtering out the signal noise: local polynomial approximation [50], low-pass recursive filters [24], Fourier transform [39, 40], modal filtering method [51], proper orthogonal decomposition [45], derivative Gaussian filter [52], spatio-temporal filter [53], gradient anisotropic diffusion filter [54]. In the present study, the processing was carried out by convolution with truncated derivative Gaussian functions, both for the time and spatial derivatives, in order to filter and 
derivate in a single operation, see Refs $[52,55]$ for details. Note that an indirect approach was also used in the present study to determine the thermal diffusivity of the material (see Section "Indirect method"). It consists of minimizing the error between experimental temperatures and theoretical temperatures provided by a selected model [56].

Compared to the direct analysis of the temperature fields that depend on particular to the specimen shape, advantage of the approach by HSR is to "remove" effects of heat dissipation due to both heat conduction within the specimen and heat exchanges with the specimen environment. The former is removed through the term $-D \partial^{2} \Theta / \partial z^{2}$ in the $1 \mathrm{D}$ approach. The latter is removed through the term $\Theta / \tau_{1 \mathrm{D}}(\Theta)$ characterizing the heat exchanges with ambient air in the 1D approach, or the term $\Theta_{0 \mathrm{D}} / \tau_{0 \mathrm{D}}\left(\Theta_{0 \mathrm{D}}\right)$ characterizing the heat exchanges with the entire environment in the 0D approach.

\section{Material and experimental setup}

NiTi medical-grade wires, $1.78 \mathrm{~mm}$ in diameter, were supplied by Fort Wayne Metals in asdrawn state with final cold work of $40 \%$. At first, a $120 \mathrm{~mm}$ long samples were placed into the hydraulic jaws of the servohydraulic Instron 8872 tensile machine so that $80 \mathrm{~mm}$ gauge length remained between the grips. Such clamped samples were then heat-treated by Joule effect using a 100 A current for 0.875 s supplied between the grips and followed by natural cooling down to the room temperature. Then, to ensure the homogeneity of the specimen 20 $\mathrm{mm}$ at each end were cut-out to obtain a specimen of $80 \mathrm{~mm}$ and a final gage length of $L=40$ $\mathrm{mm}$, as depicted in Figure 1a,b. Finally, the samples were subjected to mechanical training (not presented here) consisting of twenty superelastic loading-unloading cycles at room temperature up to $800 \mathrm{MPa}$ in force control regime at $\pm 400 \mathrm{~N} . \mathrm{s}^{-1}$. The training ensured the 
stability of the cyclic stress-strain response, which was essential for the repetitiveness of the results in our further research.

The in-situ thermography during a superelastic cycle was performed using an Infratec 8300 MWIR camera equipped with a close-up $(0.3 \mathrm{~m})$ telephoto lens $(50 \mathrm{~mm})$ and calibrated for the range [268 K,333 K] with noise equivalent temperature difference (NETD) of $20 \mathrm{mK}$ at room temperature. 1D temperature profiles along the wire were all constructed by averaging over 14 pixels in the radial direction, as compared with the 22 pixels corresponding to the wire diameter. Useful IR data were thus captured on a surface featuring an inclination angle $\varphi$ with the camera axis in the range $\pm \arcsin (14 / 22) \times 180 / \pi= \pm 40^{\circ}$, i.e., on a surface with nearly-constant thermal emissivity $\varepsilon(\varphi)$. Note that the average operation enabled us to improve the measurement resolution of the temperature. In the following, we mean by measurement resolution the change in quantity being measured that causes a change in the corresponding indication of greater than one standard deviation of the measurement noise [57]. Measurement resolution must be distinguished from the spatial and temporal resolutions, which can be defined as the minimum distance and minimum duration, respectively, between two independent measured quantities. The camera was synchronized with the loading waveform applied by the tensile machine. The samples were sprayed with high thermal emissivity (0.96) paint that was also used for painting the grips and surroundings to limit parasitic reflections. The spatial and temporal resolutions of the temperature color matrix, defined here as the size of the pixel projected on the wire and the acquisition period of time, were equal to $82.6 \mu \mathrm{m}$ and $2.86 \mathrm{~ms}$ respectively. These parameters are hereinafter denoted as $d z$ and $d t$, respectively. 


\section{Experimental identification of thermophysical}

\section{properties}

The algorithm for the heat source reconstruction requires as inputs the values of thermophysical parameters, namely, the thermal diffusivity and parameters quantifying the heat exchange between the wire and its surroundings as defined in the Background section. Hereinafter, experimental methods used to identify the thermophysical parameters are presented. Finally, the values of thermal diffusivities identified for austenite and martensite phases are presented and compared with data available in the literature.

\subsection{Heat exchange}

In Equation (2), $\tau_{1 \mathrm{D}}$ considers the heat exchanges with surrounding air only. The method used for its identification is based on preliminary homogeneous heating of the specimen suspended in the air (no contact with the jaws of the testing machine, see Figure 1c, followed by natural return to equilibrium with measurement of temperature decay recorded by the IR camera and averaged over the wire length (negligible heat conduction along $z$-axis, so $\Theta(z, t)=\Theta(t)$ ). In practice, the specimen was suspended using an adhesive tape and heated by passing electrical current through two small electrode spots $(50 \mu \mathrm{m})$ welded at both the ends. In this way, we achieved homogeneous preheating, while creating negligible heat sinks during the natural return to the ambient temperature (electrode diameter of $50 \mu \mathrm{m}$ as compared with the wire diameter of $1780 \mu \mathrm{m})$. Figure 2a shows a typical example of measured temperature decay. For homogeneous cooling of material not exhibiting any phase change, the temperature decay follows the equation (4) derived from (2) by excluding all heat sources $(s=0)$ and heat diffusion term $\left(-D \partial^{2} \Theta / \partial z^{2}=0\right)$ : 


$$
\frac{d \Theta}{d t}+\frac{\Theta}{\tau_{1 \mathrm{D}}(\Theta)}=0
$$

Parameter $\tau_{1 \mathrm{D}}(\Theta)$ in Equation (4) characterizes the ability to exchange heat with surrounding air. Temperature dependence was piecewise-fitted by exponentially decreasing curves. Figure 2a shows an example of fitted curve (in red). In practice, time intervals of $15 \mathrm{~s}$ were used. Red dots in Figure $2 \mathrm{~b}$ are the values $\tau_{1 \mathrm{D}}\left(\Theta_{i}\right)$ obtained, where $\Theta_{i}$ is the average temperature change over the time interval considered. Finally, the set of $\left(\Theta_{i}, \tau_{1 \mathrm{D}}\left(\Theta_{i}\right)\right)$ pairs were fitted by an analytical function to obtain a continuous function $\tau_{1 \mathrm{D}}(\Theta)$ : see Equation (5) and the blue dashed curve in Figure 2b. Note that the discrepancy for $\Theta_{i}$ lower than about $2 \mathrm{~K}$ is explained by the fact that the signal-to-noise ratio of the curve $\Theta(t)$ decreases more and more when the latter tends toward zero.

$$
\tau_{1 \mathrm{D}}(\Theta)=52.1+33.8 \times \exp \left(\frac{-\Theta}{5.3}\right)
$$

For comparison purposes, a constant value for $\tau_{1 \mathrm{D}}$ was also determined by fitting the complete recorded temperature curve: $\tau_{1 \mathrm{D}}=58 \mathrm{~s}$ (horizontal black line in Figure $2 \mathrm{~b}$. To quantify the increase in accuracy when considering the temperature-dependent heat exchange parameter as opposed to constant one, residual heat sources and their histograms are compared in Figure 2c,d. Heat sources are equal to zero for a natural return to ambient temperature. Residual heat sources obtained by HSR are closer to zero using $\tau_{1 \mathrm{D}}(\Theta)$ than using the constant value $\tau_{1 \mathrm{D}}=58 \mathrm{~s}$; see also the lower standard deviation of related histograms in Figure 2d. Note that even if residual heat sources are significantly greater for $\Theta$

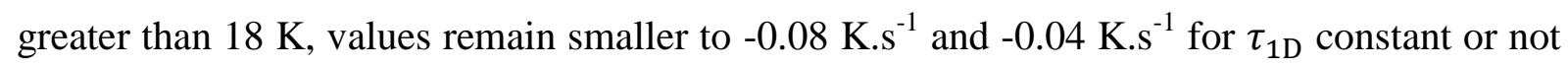
respectively, which are several orders of magnitude lower than the amplitude of the calorific events observed during the superelastic tests. 
The same procedure was applied from the configuration in Figure 1d to identify the $\tau_{0 \mathrm{D}}\left(\Theta_{0 \mathrm{D}}\right)$ function in Equation (3) considering OD HSR approach, leading to:

$$
\tau_{0 \mathrm{D}}\left(\Theta_{0 \mathrm{D}}\right)=35.5+15.7 \times \exp \left(\frac{-\Theta_{0 \mathrm{D}}}{7.7}\right)
$$

It can be noted that $\tau_{0 \mathrm{D}}<\tau_{1 \mathrm{D}}$, which is consistent with their respective definitions where $\tau_{0 \mathrm{D}}$ characterizes both heat exchanges with the air by convection and radiation with the jaws by conduction whereas $\tau_{1 \mathrm{D}}$ characterizes the convective and radiative contributions with air only. Finally, note that formulae in Equations (5) and (6) are considered as "symmetric" in the sense that $\tau_{1 \mathrm{D}}(\Theta)$ and $\tau_{0 \mathrm{D}}\left(\Theta_{0 \mathrm{D}}\right)$ become $\tau_{1 \mathrm{D}}(|\Theta|)$ and $\tau_{0 \mathrm{D}}\left(\left|\Theta_{0 \mathrm{D}}\right|\right)$ respectively. In other words, characteristic times of heat exchange are assumed to be the same below and above room temperature.

\subsection{Thermal diffusivity}

To the best knowledge of the authors, the use of thermography for the assessment of in-plane thermal diffusivity was firstly proposed in Ref. [58] using an indirect approach. In Refs [31, 44, 59-62], the authors determined the thermal properties of NiTi specimens both using conventional methods and from thermographs processed by direct approach. In the present study, both direct and indirect approaches were applied to determine the thermal diffusivities of both austenite and martensite phases. Sections "Direct method" and "Indirect method" present respectively both the methods while the following section presents identified values of thermal diffusivities of both the phases in comparison to data available in the literature.

\subsubsection{Direct method}

In practice, the specimen is clamped in jaws and locally heated by using small electrodes, 10 mm spaced as shown in Figure 1d,e,f while recorded natural cooling is reduced into a 1D 
spatiotemporal color matrix as shown also in Figure 3a. This color matrix is then used to directly calculate the thermal diffusivity from Equation (2), which in the case of no internal heat sources reduces to Equation (7) as follows:

$$
D=\frac{\frac{\partial \Theta}{\partial t}+\frac{\Theta}{\tau_{1 \mathrm{D}}(\Theta)}}{\frac{\partial^{2} \Theta}{\partial z^{2}}}
$$

Numerically, Equation (7) is evaluated using Gaussian derivative filters [52] at each pixel and at each time of region of interest (ROI) defined in space and time. Figure 3a shows the input data, i.e. the thermal field $\Theta(z, t)$. ROI was properly selected to maximize the signal-to-noise ratio (SNR) of the temperature field. This selection is in particular dictated by the evaluation of the second derivative in denominator $\partial^{2} \Theta / \partial z^{2}$ being highly sensitive to SNR. Note that during natural cooling both numerator and denominator in Equation (7) tend to zero, which is a decisive factor for time interval selection. Figure $3 \mathrm{~b}$ presents the field $D(z, t)$ related to the austenite phase of the studied material and calculated in the ROI shown in Figure 3a. Figure 3c shows the histogram of $D(z, t)$, where its mean value is considered as the value of diffusivity. Finally, the quality of thermal diffusivity identification is assessed by evaluating the residual heat sources as shown in Figure $3 \mathrm{~d}$ for the austenite phase. To quantify the quality of measurement, the average values and scatters of the histogram extracted from residual heat source color matrix were evaluated. Figure $3 \mathrm{e}$ presents a histogram of the residual heat sources obtained; the mean value of the distribution is centered at 0 and the standard deviation is about $0.02 \mathrm{~K} \cdot \mathrm{s}^{-1}$.

\subsubsection{Indirect method}

The indirect method is based on the comparison between temperature field recorded during natural cooling as described previously and theoretical temperature field calculated from a 
model. Theoretical temperature field $\theta_{\text {model }}$ is solution of the following equation including initial and boundary conditions:

$$
\begin{gathered}
\frac{\partial \theta_{\text {model }}}{\partial t}+\frac{\theta_{\text {model }}}{\tau_{1 \mathrm{D}}\left(\theta_{\text {model }}\right)}-D \frac{\partial^{2} \theta_{\text {model }}}{\partial z^{2}}=0 \\
\theta_{\text {model }}(z, 0)=\theta(z, 0) \\
\theta_{\text {model }}(0, t)=\theta(0, t) \\
\theta_{\text {model }}(L, t)=\theta(L, t)
\end{gathered}
$$

The unknown diffusivity in Equation (8) is determined from a minimization problem (12), where the absolute value of difference between theoretical and experimental temperature fields is being minimized.

$$
\left(D_{\text {aust }}\right)_{\text {indirect }}=\underset{D \in\left[10^{-8}, 10^{-4}\right]}{\operatorname{argmin}}\left(\left|\theta-\theta_{\text {model }}\right|\right)
$$

Note that experimental data are used as the initial condition (Equation (9)) and boundary conditions at the two ends of the wire $z=0$ and $z=L$ (Equations (10) and (11), respectively). The minimization problem (12) was solved in Matlab® environment using fminbnd function while Equation (8) was resolved at each iteration using the Method of Lines [63] employing Ordinary Differential Equation solver ode15s for time solver where the finite differences were used to compute spatial derivative in (8). As a measure of the quality of determination of thermal diffusivity using indirect approach, the distribution of temperature differences between measurement and model is evaluated in terms of average value and standard deviation as shown in Figure 4 for the case of austenite phase of the studied material. Note that the standard deviation, in this case, is in good agreement with NETD, i.e. the so-called measurement resolution of the IR camera given by the manufacturer.

\subsubsection{Summary on thermal diffusivity}


Table 1 presents the mean values and standard deviations of thermal diffusivity of austenite and martensite phases as measured by both the direct and indirect methods when considering both the constant and temperature-dependent heat exchange parameters. Besides, the mean values and standard deviations of residual heat sources are presented in Table 1 as accuracy quantifiers for individual determinations of the thermal diffusivity. Note that the diffusivity of martensite was also identified so that the martensite was stress-induced in NiTi sample using a prestress of $800 \mathrm{MPa}$ being above the stress level $\sigma_{t r}$ needed to stress-induced the martensite at room temperature. Therefore, the value of martensite diffusivity is related to so-called detwinned (oriented) martensite. It can be concluded from Table 1 that the values of the thermal diffusivity of austenite coincide when rounding to the first digit, while the values identified for the martensite present a scatter within the first digit. Values are compared in Table 2 with the literature. The latter shows a large scatter which can be attributed to the fact that the values were identified using different methods (DSC, Flash $3 \omega$ method) on various NiTi alloys and heat treatments. Nevertheless, we can conclude that the values from the present study are inferior to all cited values and that they match reasonably well to those in Ref. [62]. Note that to the best knowledge of the authors, literature provides values only for self-accommodating martensite while our method allows identifying the thermal diffusivity of stress-induced martensite. Therefore, the present work assessed for the first time the thermal diffusivity of detwinned martensite being higher by a factor of 1.3 compared to that of austenite.

\section{Heat sources due to stress-induced martensitic}

\section{transformation}


Heat sources due to stress-induced phase transitions were analyzed in superelastic NiTi wire by using the previously introduced HSR method. Let us recall that 20 superelastic (SE) cycles at $\pm 400 \mathrm{~N} . \mathrm{s}^{-1}$ were applied as detailed in Section "Material and experimental setup" prior to application of HSR method on the 21st SE cycle, at $\pm 20 \mathrm{~N} . \mathrm{s}^{-1}$. A lower rate was applied to limit the number of sites of the martensitic transformation nucleation thus facilitating the analysis of heat source patterns.

\subsection{Macroscopic thermomechanical response}

SE cycle consisted of loading-unloading the NiTi wire in force-control regime at $\pm 20 \mathrm{~N} . \mathrm{s}^{-1}$. Table 3 sums up all experimental setup parameters including temporal and spatial resolutions of temperature field measurements. The macroscopic thermomechanical response of the wire was evaluated in terms of stress, strain, and temperature; defined as nominal stress, engineering strain, and average temperature calculated respectively from the applied force, measured grip's displacement and spatially averaged temperature fields of the wire's gauge section. Figure 5a shows a rather typical superelastic stress-strain curve (blue line) with superimposed temperature-strain evolution (red line) showing maximum and minimum temperatures at the ends of upper and lower plateaus, respectively. These extreme values reflect near completion of the forward and reverse martensitic transformations, respectively, during which the latent heat of the phase transformation is being released and absorbed, respectively (residual austenite or martensite may have continued to transform after the stages of extreme activity of heat sources). The extreme values are close to temperature gradients reported in the literature for quasi-adiabatic loadings $[15,19,20]$. In fact, the force control loading employed in this work approaches adiabatic conditions as the forward and reverse martensitic transformation in NiTi wires proceeds via nucleation and propagation at constant stresses [7]. Therefore, high strain rates are reached during the forward and reverse 
transformation as reported in Figure 5b showing the time evolution of strain (blue line) with the superimposed time evolution of average temperature (red line) showing sharp maximum and minimum indicating the highest rate of forward and reverse martensitic transformation. Note that the high-temperature gradients reached during forward and reverse martensitic transformations lead to inclined stress plateaus that are horizontal (black dashed line in Figure 5a) for isothermal loading. The inclination is due to the temperature dependence of transformation stresses being for NiTi wires approximately $6 \mathrm{MPa} \cdot \mathrm{K}^{-1}$ [64].

\subsection{Heat sources}

HSR during the SE cycle is based on the recorded time evolution of temperature field during loading-unloading and final stress-free natural cooling. As discussed previously, the cylindrical specimen's geometry allows the dimensional reduction of the problem into 1D. Hence, the time evolution of the temperature field may be represented by a spatiotemporal color matrix, where columns are associated with time of individually recorded sample thermographs averaged in the transversal direction, while rows are associated with actual positions of material points along the wire axis. Note that the vertical spatial axis was limited to those material points that remained within the field of view during the complete SE cycle. The spatio-temporal color maps as recorded in the present work are shown in Figure 6a with superimposed time evolution of engineering axial strain responding to linear force increase/decrease during the force control loading and unloading. The color maps in Figure 6a are split by black verticals into time segments according to test stages - loading, unloading, and unloaded stage, where the sample experienced stress-free cooling. In addition, the loading and unloading segments are marked with pairs of dashed white lines delimiting the occurrence of forward and reverse martensitic transformation. Figures $6 b, c$ show in detail these zones, where the latent heat released/absorbed during forward/reverse transformation 
creates spatiotemporal temperature gradients. These temperature gradients reveal initiations of individual transformation events that clearly occur in two sequences. However, the ends of individual events cannot be resolved as they are hidden in the overall temperature change due to heat diffusion. Thanks to 1D HSR, the ends can be detected as seen in the corresponding heat source color map shown in Figure 6d,e that reveals the complete information on the spatial range and time duration of transformation events as well as on the magnitude and sign of related heat sources. As the transformation events bring about the transformation strain, the latter is superimposed in red/blue solid lines in Figure 6b-e for better interpretation of HSR in terms of phase transformation activity discussed in the next section. Note that the heat source color map was identified in two steps. First, average value of heat diffusivity from that of austenite and martensite was assumed to perform approximate HSR revealing localized transformation events, which enables to create the binary color map shown in Figure 6f. This color map clearly delimits spatio-temporal zones of near full martensite from zones from parent phase(s). Then HSR was refined by assigning the zones of near full martensite the diffusivity of martensite while the other zones were assigned the diffusivity of austenite. Heat sources identified using 0D HSR approach are reported in Figure $6 \mathrm{~g}$. Thanks to the use of OD approach allowing for a spatial integration of recorded thermographs, an evolution of heat sources lower than $1 \mathrm{~K}^{-1}{ }^{-1}$ could be successfully identified. Note that the temporal resolution (for the $0 \mathrm{D}$ and $1 \mathrm{D}$ approaches) and the spatial resolution (for the 1D approach) of the heat sources color matrix were equal to $17.2 \mathrm{~ms}$ and $744 \mu \mathrm{m}$ respectively. These values resulted from the choice of the filtering parameters detailed in Ref. [23].

\section{Heat source analysis and discussion}


HSR during SE cycle reveals the localization, kinetics, and magnitude of heat effects during solid-solid phase transformation. Applying both OD and 1D HSR approaches allowed us to identify weak heat effects as well as localized heat effects. The magnitude of heat sources (heat power density) identified at each time increment of SE cycle may be considered as a superposition of all potentially active heat sources, namely, the latent heat of phase transformations, intrinsic dissipation, and thermoelastic coupling. However, the latter will be neglected in the present discussion as it is a weak heat effect estimated to about $-0.008 \mathrm{~K} . \mathrm{s}^{-1}$ for austenite under adiabatic conditions, which is a value being on average 3 orders of magnitude lower than maxima of localized effects and 1 order of magnitude lower than weak heat sources. Considering this assumption, HSR reflects primarily the latent heat being positive in the case of the forward martensitic transformation induced by loading and negative in the case of the reverse martensitic transformation taking place upon unloading superimposed with the heat due to the intrinsic dissipation being strictly positive in both loading and unloading. Provided that these two heat sources can be distinguished, HSR can be used to track down the progress of the stress-induced martensitic transformation with a spatiotemporal resolution since the latent heat scales with the variation of the volume fraction of martensite, similarly to the transformation strain or electric resistivity.

The reconstructed localized heat sources and simultaneously measured strain evolutions in Figure 6d,e can be associated with the progress of the stress-induced martensitic transformation. Upon loading (Figure 6d), the occurrence of multiple positive heat sources along with an increase of the strain rate is an indirect evidence of the forward localized exothermic stress-induced martensitic transformation into detwinned martensitic crystalline structure bringing about a transformation strain in the direction of the loading. Upon unloading (Figure 6e), the occurrence of negative heat sources along with an increase of the magnitude of strain rate is an indirect evidence of the localized reverse endothermic stress- 
induced martensitic transformation into austenite accompanied with the recovery of the transformation strain.

\subsection{Patterns of transformation events}

HSR enables to interpret patterns of transformation events in terms of the thermomechanical coupling that is particularly strong in the case of force-controlled loading and unloading applied in the present work. Under this regime, the strain rates may become very high, particularly when the stress-induced transformation proceeds under isothermal conditions. As illustrated by the black dashed curve in Figure 5a, the isothermal response features stress plateaus associated with the forward (upper plateau) and reverse (lower plateau) martensitic transformation accompanied by transformation strains that appear and disappear when reaching the plateau stresses during forward and reverse martensitic transformation, respectively. Therefore, the transformation would theoretically occur almost instantaneously when the controlled force would have reached the transformation stress levels. However, under real non-isothermal conditions, the latent heat locally generated/absorbed by the forward/reverse transformation increases/decreases the temperature of the material volume in the neighborhood of the transforming material thus increasing/decreasing the stress (Figure $6 \mathrm{~b}, \mathrm{c})$ required to transform the neighboring material volume since the transformation stress is temperature-dependent. Consequently, the superelastic response becomes rate-dependent, as illustrated in Figure 5a comparing theoretical isothermal stress-strain curve (black dashed curve) with stress-strain response measured under force-controlled regime (blue solid curve) [12-20].

\subsubsection{Forward martensitic transformation}


In the case of the loading (Figure 6b), the fast martensite nucleation leads to local heating of surrounding not yet transformed material thus increasing locally the transformation stress approximately by a factor of $6 \mathrm{MPa}^{-1}$ [64]. Consequently, the propagation of martensite band fronts into their surrounding is hindered since the stress required for the forward transformation has been locally increased in this volume. As a result, a new nucleation site is created at a distant location not affected by released latent heat. These processes of nucleation bursts and transformation arrests proceed along the axis of the wire as seen in Figure $6 \mathrm{~d}$ where the reconstructed heat sources 1-10 represent the nucleation sites. The nucleated martensite bands bring about the transformation strain, which adds up to the elastic strain and increases the measured strain rate, as confirmed by strain measurement overlapped in Figure 6d. As a result of the sequence of 10 transformation nucleation events, the temperature of the sample is homogeneously increased by $12 \mathrm{~K}$, which leads to an increase of transformation

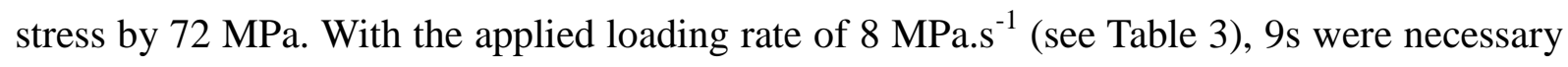
after the first burst to reach the increased transformation stress. During this period of time, the martensitic transformation was indeed suppressed as indicated in Figure $6 \mathrm{~b}$ by the absence of heat sources and a decrease in strain rate. Finally, when the increased transformation stress was reached pairs of martensite band fronts from adjacent nucleation sites start to propagate until they merge. This proceeded again sequentially in locations 11-20 due to the effect of local temperature changes as in the case of the nucleation sequence.

\subsubsection{Reverse martensitic transformation}

Analogically to the forward martensitic transformation, the reverse transformation proceeded in two stages - austenite sequential nucleation in locations 21-30 (Figure 6e), followed by a short band fronts propagation, and sequential merging of martensite bands in locations 31-41 by austenite band fronts propagations from nucleation sites. The evolution of strain during the 
reverse transformation confirms this process as the magnitude of the negative strain rate increased during the sequences of nucleation and band fronts propagations.

\subsubsection{Summary}

To sum up, the local temperature changes due to latent heat release/absorption lead first to sequential forward/reverse martensitic transformation nucleated at several nearly equidistantly located sites. These events are followed by short propagations of band fronts that are arrested by a homogeneous increase/decrease of the sample temperature as the thermodynamic conditions for martensitic transformation are not satisfied. The transformation via merging of martensite band fronts is completed only after the controlled external tensile force reaches the transformation stress at actual increased/decreased temperature. The sites of nucleation and band front merger can be characterized through its width along the wire axis, kinetics, and magnitude of heat sources. A characteristic width of these events was identified to be in all cases similar to the diameter size (see Figure $7 \mathrm{~b}$-e and Figure 8d,e), which is in agreement with the size of the martensite band front analyzed in detail by 3D-XRD method in Ref. [35].

\subsection{Weak heat sources prior and post localized heat effects}

Weak heat sources were identified in time intervals, indicated by "0D approach" in Figure 6g, where no local heat sources were active. The weak heat sources were about 100 times lower than the localized heat effects. Positive weak heat sources were identified during the loading stage, where they progressively increased during the loading prior to the appearance of the localized heat sources. The weak heat sources reappeared and exponentially decreased during loading when the activity of localized heat sources ceased. During unloading, the negative weak heat sources appeared with an increased magnitude prior to the appearance of the 
localized heat sources. Weak heat sources reappeared again when the activity of the localized heat events ceased.

The identified weak heat sources cannot be solely due to thermoelasticity since the weak heat sources are positive during loading and negative during unloading, i.e., the signs are inversed in comparison to temperature effects due to the thermoelasticity. The weak sources may be signs of martensitic transformation initiated prematurely at sites of the microstructure with preferable conditions for the transformation induced by previous training. The positive heat effects during loading prior to the localized heat effects might also be assigned to austenite-Rphase transformation $[21,29,64,65]$, transformation paths established by the previous training [33] or other precursors events. Although the intensity of these heat sources is weak, the amount of heat generated or absorbed was non-negligible as they were active for longer time compared to the localized heat sources. The intensities of heat sources are discussed in the following section.

\subsection{Spatiotemporal distributions and intensities of heat sources}

As discussed previously, the recorded localized heat sources may be categorized into four types of events: martensite nucleation and merging events appearing upon loading at locations 1-10 and 11-20, respectively, as shown in Figure 6d; austenite nucleation and merging events appearing upon unloading at locations 21-30 and 31-41, respectively, as shown in Figure 6e. The shape of spatiotemporal distributions of martensite nucleation/merging and austenite nucleation events are comparable but different from the distribution of austenite merging events as illustrated in Figure 7. The austenite merging event in Figure $7 \mathrm{~d}$ is more diffused in time compared to other events in Figure 7a-c. It features a characteristic elliptical shape with major axis aligned with the time-axis as shown by contour lines of heat sources $31-41$ in 
Figure 6e. This was found to be characteristic for all austenite merging events. In a sharp contrast, the spatiotemporal color maps of other events in figures $7 \mathrm{a}-\mathrm{c}$ feature rather circular shapes as underlined by contour lines of heat sources 1-30 in Figure 6d,e.

For the statistical treatment of individual events, horizontal and vertical cross-sections through the maxima of spatiotemporal distributions were considered as illustrated in Figure 7a. The horizontal cross-sections reflecting the temporal distributions of heat sources were averaged for all events of the same type and plotted in Figure 8a, where standard deviations of their maxima are also shown. The comparison of temporal distributions in Figure 8a confirms that the austenite merging events are more spread in time compared to other types. To characterize the localized events, averages and standard deviations of FWHM (Full Width at Half Maximum) of temporal distributions were evaluated in Figure $8 b$ for individual types of localized heat sources. It shows that FWHM of the austenite merging events is twice as large compared to other events.

The vertical cross-sections of localized heat effects were used to evaluate the average spatial distributions and standard deviations at their maxima as plotted in Figure 8d. The comparison of spatial distributions in Figure 8d shows no substantial difference in the size and shape of heat source events, which is confirmed by Figure 8e comparing averages and standard deviations of the FWHM evaluated on spatial distributions of individual types of events. Considering the conical-shaped martensite band front in NiTi wires reported in [35], Figure 8f plausibly explains the shape of spatial distributions by suggesting cross-sectional geometries of transforming volumes along the wire axis giving rise to the localized heat sources. In fact, two types of cross-sectional geometries may be formed by two adjacent conical interfaces: either a concave shape in the case of martensite nucleation and austenite merging (see MNE and AME in Figure 8f) or a lenticular shape in the case of martensite merging and austenite 
nucleation (see MME and ANE in Figure 8f). Localized heat sources of both geometries are indeed spatially most intensive in the center of transforming volumes and tend to vanish towards both interfaces thus giving rise to a Gaussian type of spatial distributions. The magnitudes of spatial distributions are, however, different similarily to temporal distributions shown in Figure 8a.

To evaluate heat, time integration of the heat sources was performed. Note that in agreement with the used heat source units $\left(\mathrm{K}_{\mathrm{s}} \mathrm{s}^{-1}\right)$, the heat intensities are evaluated in Kelvin thus expressing temperature changes that the heat sources would cause to the sample under adiabatic conditions. Figure $8 \mathrm{c}$ shows the average values and standard deviations of intensities for all types of localized events (red and blue indicators) and for the weak heat sources WHS 1-4 (black indicators) identified in four-time windows shown in Figure 6g. The intensities are proportional to magnitudes of heat sources and duration of their activities and, therefore, the weak heat sources released a non-negligible amount of heat compared to localized heat sources as they were active for considerably longer times. Figure $8 \mathrm{c}$ shows that the intensities of localized heat sources active during loading (martensite nucleation and merging) are on average higher than those active upon unloading (austenite nucleation and merging). On the one hand, this may be explained by different latent heats associated with the forward and reverse transformations as observed by HSR [65] and DSC measurement [66]. On the other hand, in case of mechanically driven martensitic transformation, this difference can be due to the intrinsic dissipation accompanying the forward and reverse martensitic transformation under stress. As the intrinsic dissipation is always positive, it increases the amount of heat generated upon loading but decreases the amount of heat absorbed upon unloading. 
Finally, it is interesting to note that the intensities of nucleation and merging events are different as evidenced by the distinct heights of red and blue indicators in Figure $8 \mathrm{c}$. The difference is much more pronounced for the reverse transformation, i.e., austenite nucleation and merging, compared to forward transformation, where the average values differ within the standard deviations. These differences suggest that each type of the event is accompanied by a release of a different amount of dissipative heat. The dissipative heat cannot be exactly determined from the present experimental data as the values of the latent heat released or absorbed during localized events are unknown. Nevertheless, the dissipative heat can be estimated under the conservative assumption that the dissipative heat is equally distributed between the forward and reverse transformation and that the latent heat of the forward and reverse transformation is constant. In such a case, the latent heat corresponds to the average value of intensities evaluated for the 4 types of events. Such estimated latent heat is plotted with horizontal dashed line Figure $8 \mathrm{c}$. The dissipative heats associated with the 4 types of events are then the differences denoted by black hatched bars in Figure 8c. The austenite merging events are associated with a twice as large amount of dissipative heat compared to austenite nucleation events.

Note that the comparison of dissipative heat associated to forward and reverse martensitic transformations cannot be reliably performed here as the value of the latent heat was estimated only. Nevertheless, this uncertainty does not affect the relative comparisons between nucleation and merging events of either forward or reverse martensitic transformation. The same applies to the evaluation of an average relative intrinsic dissipation associated with the localized events, which was evaluated to be $25 \%$ of the estimated latent heat by averaging relative intrinsic dissipation of individual events.

\subsection{Summary of results}


The results can be summarized as follows:

1. The forward martensitic transformation during tensile loading proceeds in two stages. In the first stage, martensite bands nucleate sequentially at multiple equidistant locations along the wire and propagate along the wire. The series of nucleation events, however, gives rise to quasi-homogeneous heating of the volume of the wire between the nucleation sites. The temperature increasing in this volume causes a temporary transformation arrest during which the external stress required to drive the transformation increases. In the second stage, the transformation is completed by sequence of merging events in which two martensite band fronts propagating from the neighboring nucleation sites merge and the austenite disappears.

2. The series of nucleation and merging events are clearly evidenced by the appearance of the localized heat sources and the increase of the macroscopic strain rate.

3. Reverse martensitic transformation during unloading proceeds analogically to forward transformation but the heat bursts are negative.

4. The method allowed for detailed statistical analysis of the observed localized heat sources with respect to the type of events giving the following results.

a) The integral intensity of localized heat sources corresponding to nucleation events is higher compared to the merging events.

b) The integral intensity of localized heat sources related to forward martensitic transformation is higher compared to that of reverse transformation.

c) The austenite merging events corresponding to the reverse transformation are more spread in time compared to other events.

d) The observed heat sources correspond to sum of latent heat due to martensitic transformation and intrinsic dissipation accompanying the progress of the 
transformation. The intrinsic dissipation associated with the nucleation and merging events is estimated to be $\sim 25 \%$ of the released/absorbed latent heat.

e) The austenite merging events during the reverse transformation are associated with higher intrinsic dissipation compared to preceding austenite nucleation events.

f) The shape of spatial distributions of the localized heat effects correlates with the conical shape of austenite-martensite interface observed experimentally in Ref. [35].

5. The localized martensitic transformation (from the nucleation to the merging heat bursts) are preceded and followed by weak heat effects (positive during loading and negative during unloading) associated with homogeneously proceeding martensitic transformations that precede and follow the heat bursts. The amounts of heat generated/absorbed by the weak heat sources are two orders of magnitude lower compared to the heat generated/absorbed by the localized martensitic transformation. However, since they last longer, the total amounts of heat generated/absorbed by the weak heat sources correspond to $10-40 \%$ of the heat generated/absorbed by the localized martensitic transformation.

\section{Conclusion}

Heat sources induced by the deformation processes activated in a trained superelastic nickeltitanium wire subjected to a force-controlled tensile loading-unloading superelastic cycle were analyzed using a heat source reconstruction method. Particular attention was paid to the evaluation of the heat exchanges of the specimen with its environment and the thermal diffusivity that was found $30 \%$ higher for detwinned martensite compared to austenite. The latent heat generated/absorbed during the forward/reverse martensitic transformation induced by the force-controlled cycle leads to strong thermomechanical coupling that drives the 
formation of the spatio-temporal distribution of localized transformation patterns and affects the stress-strain response of the SMA wire. The method allows for tracking the progress of the localized stress-induced martensitic transformation. Sequentially appearing patterns of localized transformation events of four types were identified. Upon loading, the events were associated with nucleations of martensite bands and their subsequent merging. Analogically, the events associated with nucleations of austenite bands and their subsequent merging were identified upon unloading. In addition, weak heat sources observed before and after the heat bursts were associated with the homogeneous martensitic transformation. The intrinsic dissipation heat associated with the nucleation and merging events, which is positive on both loading and unloading, is estimated to be $\sim 25 \%$ of the released/absorbed latent heat.

\section{Acknowledgments}

This publication was supported by OP RDE, MEYS, under the project "European Spallation Source - participation of the Czech Republic - OP", "Reg. No. CZ.02.1.01/0.0/0.0/16_013/0001794”. P. Šittner and L. Heller kindly acknowledge the support of the research from Czech Science Foundation (CSF) project 18-03834S. M. Karlik acknowledges the financial support of the ERDF in the frame of the Project No. CZ.02.1.01/0.0/0.0/15_003/0000485. Finally, A. Jury acknowledges the support received from the Agence Nationale de la Recherche of the French government through the program “Investissements d'Avenir" (16-IDEX-0001 CAP 20-25).

\section{Compliance with Ethical Standards}

Conflict of interests The authors declare that they have no conflict of interest. 


\section{References}

1. Otsuka K, Wayman CM (1999) Shape Memory Materials. Cambridge University Press, Cambridge, UK.

2. Lagoudas DC (2010) Shape Memory Alloys: Modeling and Engineering Applications. Springer Science, New York, USA.

3. Lexcellent C (2013) Shape-Memory Alloys Handbook. John Wiley \& Sons, Hoboken, NJ, USA.

4. Yoneyama T, Miyazaki S (2009) Shape memory alloys for biomedical applications. Woodhead Publishing, Cambridge, England.

5. Racek J, Stora M, Šittner P, Heller L, Kopeček J, Petrenec M (2015) Monitoring Tensile Fatigue of Superelastic NiTi Wire in Liquids by Electrochemical Potential. Shap Mem Superelasticity 1:204-230. https://doi.org/10.1007/s40830-015-0020-5

6. Miyazaki S, Imai T, Otsuka K, Suzuki Y (1981) Lüders-like deformation observed in the transformation pseudoelasticity of a Ti-Ni alloy. Scr Metall 15:853-856. https://doi.org/10.1016/0036-9748(81)90265-9

7. Shaw JA, Kyriakides S (1995) Thermomechanical aspects of NiTi. J Mech Phys Solids 43:1243-1281. https://doi.org/10.1016/0022-5096(95)00024-D

8. Shaw JA, Kyriakides S (1997) Initiation and propagation of localized deformation in elasto-plastic strips under uniaxial tension. Int J Plasticity 13:837-871. https://doi.org/10.1016/S0749-6419(97)00062-4

9. Sittner P, Liu Y, Novak V (2005) On the origin of Lüders-like deformation of NiTi shape memory alloys. J Mech Phys Solids 53:1719-1746. https://doi.org/10.1016/J.JMPS.2005.03.005

10. Dutta SC, Majumder R (2019) Shape Memory Alloy (SMA) as a Potential Damper in Structural Vibration Control. In: Hloch S \& Al. (Eds) Advances in Manufacturing Engineering and Materials. Lecture Notes in Mechanical Engineering. Springer, Cham, pp 485-492. https://doi.org/10.1007/978-3-319-99353-9_51

11. Daly S, Ravichandran G, Bhattacharya K (2007) Stress-induced martensitic phase transformation in thin sheets of Nitinol. Acta Mater 55:3593-3600. https://doi.org/10.1016/j.actamat.2007.02.011

12. Pieczyska EA, Gadaj SP, Nowacki WK, Tobushi H (2004) Thermomechanical Investigations of Martensitic and Reverse Transformations in TiNi Shape Memory Alloy. B Pol Acad Sci-Tech 52: 165-171. http://www.ippt.pan.pl/Repository/o6480.pdf 13. Pieczyska EA, Gadaj SP, Nowacki WK, Tobushi H (2006) Phase-Transformation Fronts 
Evolution for Stress- and Strain-Controlled Tension Tests in TiNi Shape Memory Alloy. Exp Mech 46:531-542. https://doi.org/10.1007/s11340-006-8351-y

14. Pieczyska EA (2010) Activity of stress-induced martensite transformation in TiNi shape memory alloy studied by infrared technique. J Mod Optic 57:1700-1707. https://doi.org/10.1080/09500341003725748

15. He Y, Sun Q (2014) On non-monotonic rate dependence of stress hysteresis of superelastic shape memory alloy bars. Int J Solids Struct 48:1688-1695. https://doi.org/10.1016/j.ijsolstr.2011.02.017

16. Takeda K, Tobushi H, Pieczyska EA (2012) Transformation-Induced Creep and Creep Recovery of Shape Memory Alloy. Materials 5:909-921. https://doi.org/10.3390/ma5050909

17. Pieczyska EA, Tobushi H, Kulasiński K (2013) Development of transformation bands in TiNi SMA for various stress and strain rates studied by a fast and sensitive infrared camera. Smart Mater Struct 22:035007. https://doi.org/10.1088/0964-1726/22/3/035007

18. Yin H, He Y, Sun Q (2014) Effect of deformation frequency on temperature and stress oscillations in cyclic phase transition of NiTi shape memory alloy. J Mech Phys Solids 67:100-128. https://doi.org/10.1016/J.JMPS.2014.01.013.

19. Ahadi A, Sun Q (2014) Effects of grain size on the rate-dependent thermomechanical responses of nanostructured superelastic NiTi. Acta Mater 76: 186-197. https://doi.org/10.1016/j.actamat.2014.05.007

20. Pieczyska EA, Staszczak M, Dunić V, Slavković R, Tobushi H, Takeda K (2014) Development of Stress-Induced Martensitic Transformation in TiNi Shape Memory Alloy. J Mater Eng Perform 23:2505-2514. https://doi.org/10.1007/s11665-014-0959-y

21. Alarcon Tarquino EA (2018) Structural fatigue of superelastic NiTi wires. PhD dissertation, Université de Bretagne Occidentale, France.

22. Dunić V, Pieczyska EA, Kowalewski ZL, Matsui R, Slavković R (2019) Experimental and Numerical Investigation of Mechanical and Thermal Effects in TiNi SMA during Transformation-Induced Creep Phenomena. Materials 12:883. https://doi.org/10.3390/ma12060883

23. Jury A, Balandraud X, Heller L, Alarcon E, Karlik M (2020) One-dimensional heat source reconstruction applied to phase transforming superelastic Ni-Ti wire. In: Baldi A et al. (Eds.) Residual Stress, Thermomechanics \& Infrared Imaging and Inverse Problems, Volume 6, Conference Proceedings of the Society for Experimental Mechanics Series, pp 36-40, Springer, Cham. https://doi.org/10.1007/978-3-030-30098-2_6

24. Balandraud X, Chrysochoos A, Leclercq S, Peyroux R (2001) Influence of the 
thermomechanical coupling on the propagation of a phase change front. C R Acad SciSer IIB - Mech 329:621-626. https://doi.org/10.1016/S1620-7742(01)01376-9

25. Delpueyo D, Balandraud X, Grédiac M (2011) Applying infrared thermography to analyse martensitic microstructures in a $\mathrm{Cu}-\mathrm{Al}-\mathrm{Be}$ shape-memory alloy subjected to a cyclic loading. Mater Sci Eng A 528:8249-8258. https://doi.org/10.1016/J.MSEA.2011.07.050

26. Louche H, Schlosser P, Favier D, Orgéas L (2012) Heat Source Processing for Localized Deformation with Non-Constant Thermal Conductivity. Application to Superelastic Tensile Tests of NiTi Shape Memory Alloys. Exp Mech 52:1313-1328. https://doi.org/10.1007/s11340-012-9607-3

27. Chrysochoos A, Chezeaux J-C, Caumon H (1989) Thermomechanical behavior law analysis by infrared thermography. Rev Phys Appl 24:215-225. https://doi.org/10.1051/rphysap:01989002402021500

28. Schlosser P, Louche H, Favier D, Orgeas L (2007) Image processing to estimate the heat sources related to phase transformations during tensile tests of NiTi tubes. Strain 43:260271. https://doi-org.insis.bib.cnrs.fr/10.1111/j.1475-1305.2007.00350.x

29. Favier D, Louche H, Schlosser P, Orgeas L, Vacher P, Debove L (2007) Homogeneous and heterogeneous deformation mechanisms in an austenitic polycrystalline Ti-50.8 at.\% $\mathrm{Ni}$ thin tube under tension. Investigation via temperature and strain fields measurements. Acta Mater 55: 5310-5322. https://doi.org/10.1016/j.actamat.2007.05.027

30. Chrysochoos A, Löbel M, Maisonneuve O (1995) Thermomechanical coupling of pseudoelastic behavior of CuZnAl and NiTi alloys. C R Acad Sci II 320(5):217-223

31. Delobelle V (2012) Contributions à l'étude thermomécanique des alliages à mémoire de forme NiTi et à la réalisation par soudage de matériaux architecturés NiTi. PhD dissertation, Université de Grenoble, France

32. De Oliveira HMR (2018) Study of thermomechanical couplings in nanostructured superelastic nickel-titanium wires. PhD dissertation, Université de Grenoble, France.

33. Brinson LC, Schmidt I, Lammering R (2004) Stress-induced transformation behavior of a polycrystalline NiTi shape memory alloy: micro and macromechanical investigations via in situ optical microscopy. J Mech Phys Solids 52:1549-1571. https://doi.org/10.1016/J.JMPS.2004.01.001

34. He YJ, Sun QP (2010) Rate-dependent domain spacing in a stretched NiTi strip. Int J Solids Struct 47:2775-2783. https://doi.org/10.1016/J.IJSOLSTR.2010.06.006

35. Sedmák P, Pilch J, Heller L, Kopeček J, Wright J, Sedlák P, Frost M, Šittner P (2016) Grain-resolved analysis of localized deformation in nickel-titanium wire under tensile 
load. Science 353:559-62. https://doi.org/10.1126/science.aad6700

36. Zheng L, He Y, Moumni Z (2016) Effects of Lüders-like bands on NiTi fatigue behaviors. Int J Solids Struct 83:28-44. https://doi.org/10.1016/J.IJSOLSTR.2015.12.021

37. Heller L, Šittner P, Sedlák P, Seiner H, Tyc O, Kadeřávek L, Sedmák P, Vronka M (2019) Beyond the strain recoverability of martensitic transformation in NiTi. Int J Plasticity 116:232-264. https://doi.org/10.1016/J.IJPLAS.2019.01.007

38. Dunić V, Pieczyska EA, Tobushi H, Staszczak M, Slavković R (2014) Experimental and numerical thermo-mechanical analysis of shape memory alloy subjected to tension with various stress and strain rates. Smart Mater Struct 23:055026. https://doi.org/10.1088/0964-1726/23/5/055026

39. Chrysochoos A, Louche H (2000) An infrared image processing to analyse the calorific effects accompanying strain localisation. Int J Eng Sci 38:1759-1788. https://doi.org/10.1016/S0020-7225(00)00002-1

40. Louche H, Chrysochoos A (2001) Thermal and dissipative effects accompanying Lüders band propagation. Mater Sci Eng A 307:15-22. https://doi.org/10.1016/S09215093(00)01975-4

41. Wattrisse B, Muracciole JM, Chrysochoos A (2002) Thermomechanical effects accompanying the localized necking of semi-crystalline polymers. Int J Therm Sci 41:422-427. https://doi.org/10.1016/S1290-0729(02)01334-0

42. Connesson N, Maquin F, Pierron F (2011) Experimental Energy Balance During the First Cycles of Cyclically Loaded Specimens Under the Conventional Yield Stress. Exp Mech 51, 23-44. https://doi-org.insis.bib.cnrs.fr/10.1007/s11340-010-9336-4

43. Blanche A, Chrysochoos A, Ranc N, Favier V (2015) Dissipation Assessments During Dynamic Very High Cycle Fatigue Tests. Exp Mech 55: 699-709. https://doiorg.insis.bib.cnrs.fr/10.1007/s11340-014-9857-3

44. Delobelle V, Favier D, Louche H, Connesson N (2015) Determination of Local Thermophysical Properties and Heat of Transition from Thermal Fields Measurement During Drop Calorimetric Experiment. Exp Mech 55: 711-723. https://doiorg.insis.bib.cnrs.fr/10.1007/s11340-014-9877-z

45. Ranc N, Blanche A, Ryckelynck D, Chrysochoos A (2015) POD Preprocessing of IR Thermal Data to Assess Heat Source Distributions. Exp Mech 55:725-739. https://doi.org/10.1007/s11340-014-9858-2

46. Wang XG, Wang L, Huang MX (2017) Kinematic and thermal characteristics of Lüders and Portevin-Le Châtelier bands in a medium Mn transformation-induced plasticity steel. Acta Mater 124:17-29. https://doi.org/10.1016/J.ACTAMAT.2016.10.069 
47. Jongchansitto P, Douellou C, Preechawuttipong I, Balandraud X (2019) Comparison between $0 \mathrm{D}$ and $1 \mathrm{D}$ approaches for mechanical dissipation measurement during fatigue tests. Strain 55:e12307. https://doi.org/10.1111/str.12307

48. Chrysochoos A, Pham H, Maisonneuve O (1996) Energy balance of thermoelastic martensite transformation under stress. Nucl Eng Des 162:1-12.

https://doi.org/10.1016/0029-5493(95)01140-4

49. Delpueyo D, Balandraud X, Grédiac M, Stanciu S, Cimpoesu N (2018) A specific device for enhanced measurement of mechanical dissipation in specimens subjected to long-term tensile tests in fatigue. Strain 54:e12252. https://doi.org/10.1111/str.12252

50. Pastor ML, Balandraud X, Grédiac M, Robert JL (2008) Applying infrared thermography to study the heating of 2024-T3 aluminium specimens under fatigue loading. Infrared Phys Technol 51:505-515. https://doi.org/10.1016/J.INFRARED.2008.01.001

51. Pottier T, Louche H, Samper S, Favreliere H, Toussaint F, Vacher P (2014) Proposition of a modal filtering method to enhance heat source computation within heterogeneous thermomechanical problems. Int J Eng Sci 81:163-176. https://doi.org/10.1016/J.IJENGSCI.2014.04.010

52. Delpueyo D, Balandraud X, Grédiac M (2013) Heat source reconstruction from noisy temperature fields using an optimised derivative Gaussian filter. Infrared Phys Technol 60:312-322. https://doi.org/10.1016/J.INFRARED.2013.06.004

53. Corvec G, Robin E, Le Cam JB, Sangleboeuf JC, Lucas P (2016) Improving spatiotemporal resolution of infrared images to detect thermal activity of defect at the surface of inorganic glass. Infrared Phys Technol 77:193-202. https://doi.org/10.1016/J.INFRARED.2016.05.026

54. Beitone C, Balandraud X, Delpueyo D, Grédiac M (2017) Heat source reconstruction from noisy temperature fields using a gradient anisotropic diffusion filter. Infrared Phys Technol 80:27-37. https://doi.org/10.1016/J.INFRARED.2016.11.003

55. Witkin AP (1987) Scale-space filtering. In: Fischle AM, Firschein O (Eds) Readings in Computer Vision. Elsevier. Chapter 2, pp 329-332. https://doi.org/10.1016/B978-0-08051581-6.50036-2

56. Renault N, André S, Maillet D, Cunat C (2010) A spectral method for the estimation of a thermomechanical heat source from infrared temperature measurements. Int J Therm Sci 49:1394-1406. https://doi.org/10.1016/J.IJTHERMALSCI.2010.03.001

57. Chrysochoos A, Surrel Y (2012) Basics of Metrology and Introduction to Techniques, in: Grédiac M, Hild F (Eds) Full-Field Measurements and Identification in Solid Mechanics. John Wiley \& Sons, Inc., Hoboken, NJ, USA, Chapter 1, pp 1-30. 
https://doi.org/10.1002/9781118578469.ch1

58. Philippi I, Batsale JC, Maillet D, Degiovanni A (1995) Measurement of thermal diffusivities through processing of infrared images. Rev Sci Instrum 66:182-192. https://doi.org/10.1063/1.1146432

59. Rohde M, Schüssler A (1997) On the response-time behaviour of laser micromachined NiTi shape memory actuators. Sensors Actuat A-Phys 61:463-468. https://doi.org/10.1016/S0924-4247(97)80306-8

60. Faulkner MG, Amalraj JJ, Bhattacharyya A (2000) Experimental determination of thermal and electrical properties of Ni-Ti shape memory wires. Smart Mater Struct 9:632-639. https://doi.org/10.1088/0964-1726/9/5/307

61. Zanotti C, Giuliani P, Riva G, Tuissi A, Chrysanthou A (2009) Thermal diffusivity of NiTi SMAs. J Alloys Compd 473:231-237. https://doi.org/10.1016/J.JALLCOM.2008.05.040

62. Zanotti C, Giuliani P, Chrysanthou A (2012) Martensitic-Austenitic phase transformation of Ni-Ti SMAs: Thermal properties. Intermetallics 24:106-114. https://doi.org/10.1016/J.INTERMET.2012.01.026

63. Meyer GH (2015) Chapter 2: The Method of Lines (MOL) for the Diffusion Equation. In: The Time-Discrete Method of Lines for Options and Bonds. World Scientific Publishing Co. Pte. Ltd., Singapore, pp 57-74. https://doi.org/10.1142/9789814619684_0002

64. Šittner P, Landa M, Lukáš P, Novák V (2006) R-phase transformation phenomena in thermomechanically loaded NiTi polycrystals. Mech Mater 38:475-492. https://doi.org/10.1016/J.MECHMAT.2005.05.025

65. De Oliveira HMR, Louche H, Grassi END, Favier D (2020) Specific forward/reverse latent heat and martensite fraction measurement during superelastic deformation of nanostructured NiTi wires. Mater Sci Eng A 774:138928. https://doi.org/10.1016/j.msea.2020.138928

66. Shaw J, Churchill C, Iadicola MA (2008) Tips and tricks for characterizing shape memory alloy wire: Part 1 - Differential scanning calorimetry and basic phenomena. Exp Techniques 32:55-62. https://doi.org/10.1111/j.1747-1567.2008.00410.x 
a)

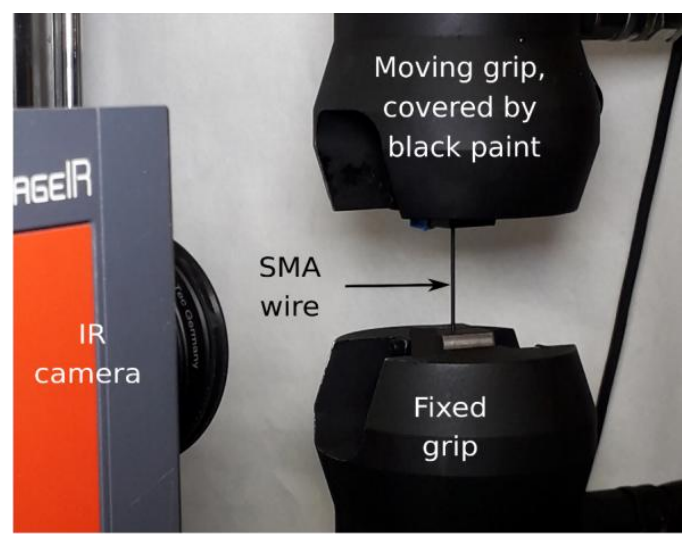

b)

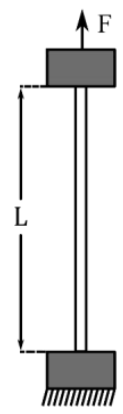

d)

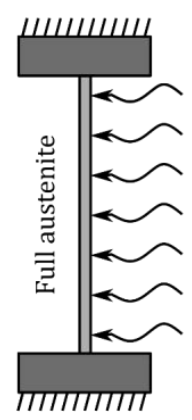

e)

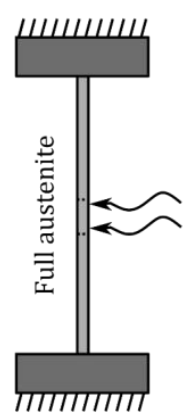

Preliminary
homogeneous heating

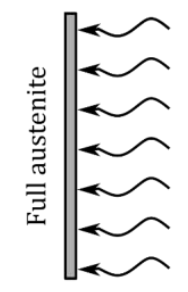

f)

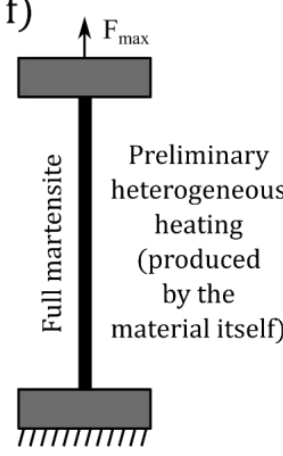

Fig. 1 Experimental setups: (a) photograph of SMA wire clamped in hydraulic jaws with installed IR camera; (b) schematic view of a wire clamped in steel jaws. Figs $\mathrm{c}$ to $\mathrm{f}$ show schemes for identification of thermophysical parameters to measure (c) characteristic time of heat exchange with surrounding air; (d) characteristic time of heat exchange with entire surroundings i.e. air and jaws; (e) thermal diffusivity of the austenite phase; (f) thermal diffusivity of the martensite phase. 

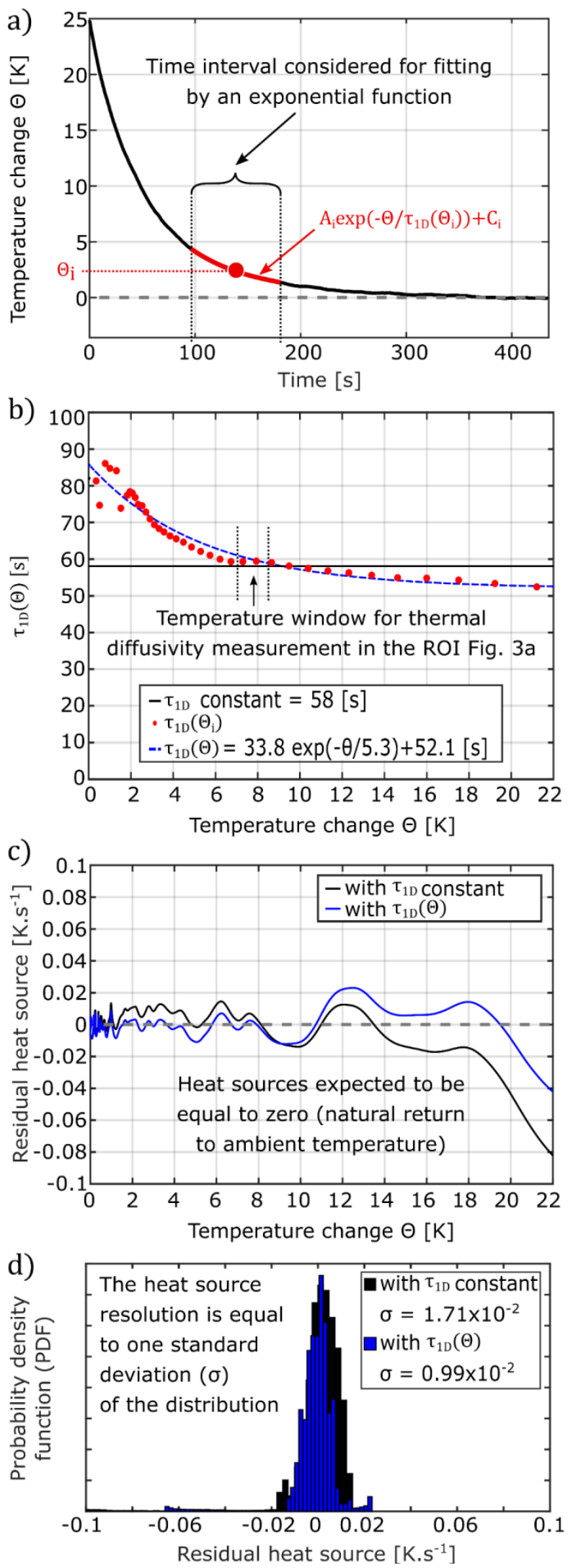

Fig. 2 (a) Natural cooling of the specimen in the configuration depicted in Fig. 1c; (b) constant and temperature-dependent characteristic times of heat exchange with the surrounding air; (c) time evolutions of residual heat sources; (d) histograms of residual heat sources. 
a)
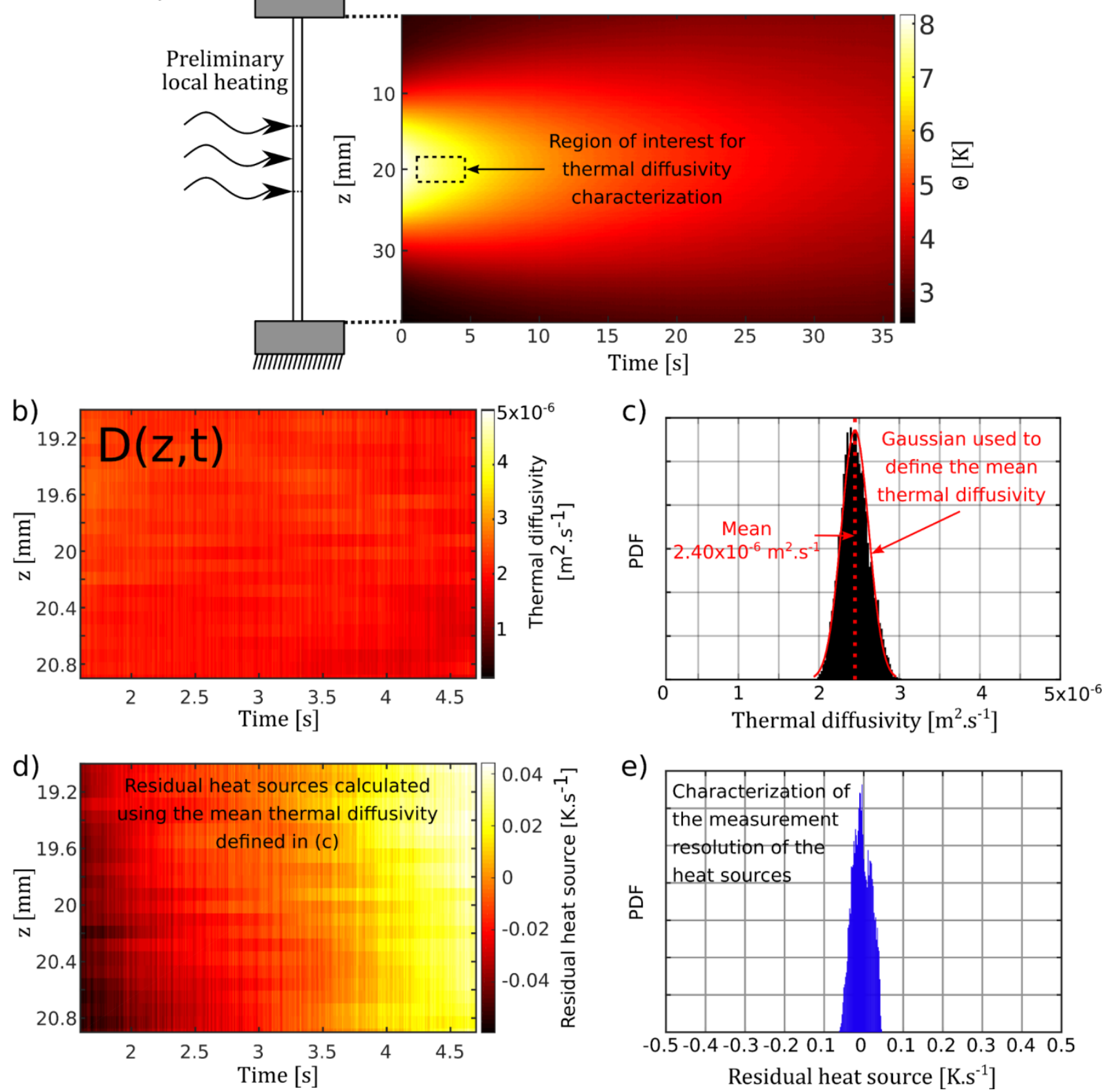

Fig. 3 (a) Temperature color matrix after preliminary local heating as depicted in Fig. 1e and spatiotemporal region of interest (ROI) for identification of the austenite thermal diffusivity; (b) thermal diffusivity color matrix determined by direct method on the ROI; (c) thermal diffusivity histogram over the ROI; (d) color matrix of residual heat sources evaluated on the ROI; (e) residual heat source histogram over the ROI. 


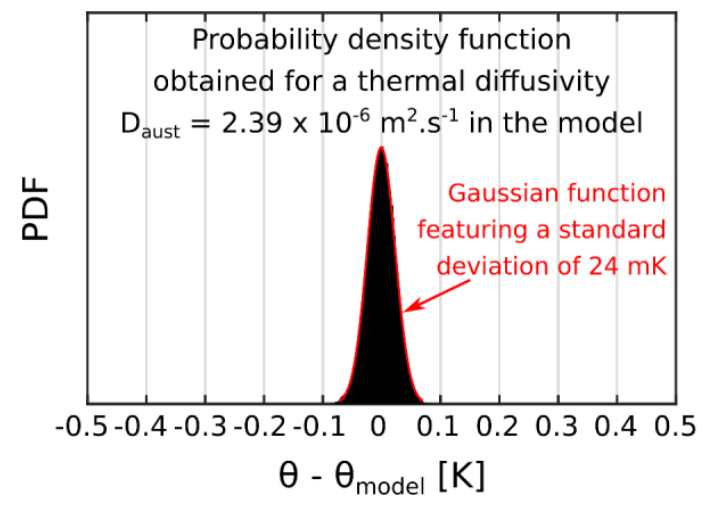

Fig. 4 Statistical mismatch between measured temperatures and theoretical temperatures calculated using the thermal diffusivity of the austenite phase estimated by indirect method. 

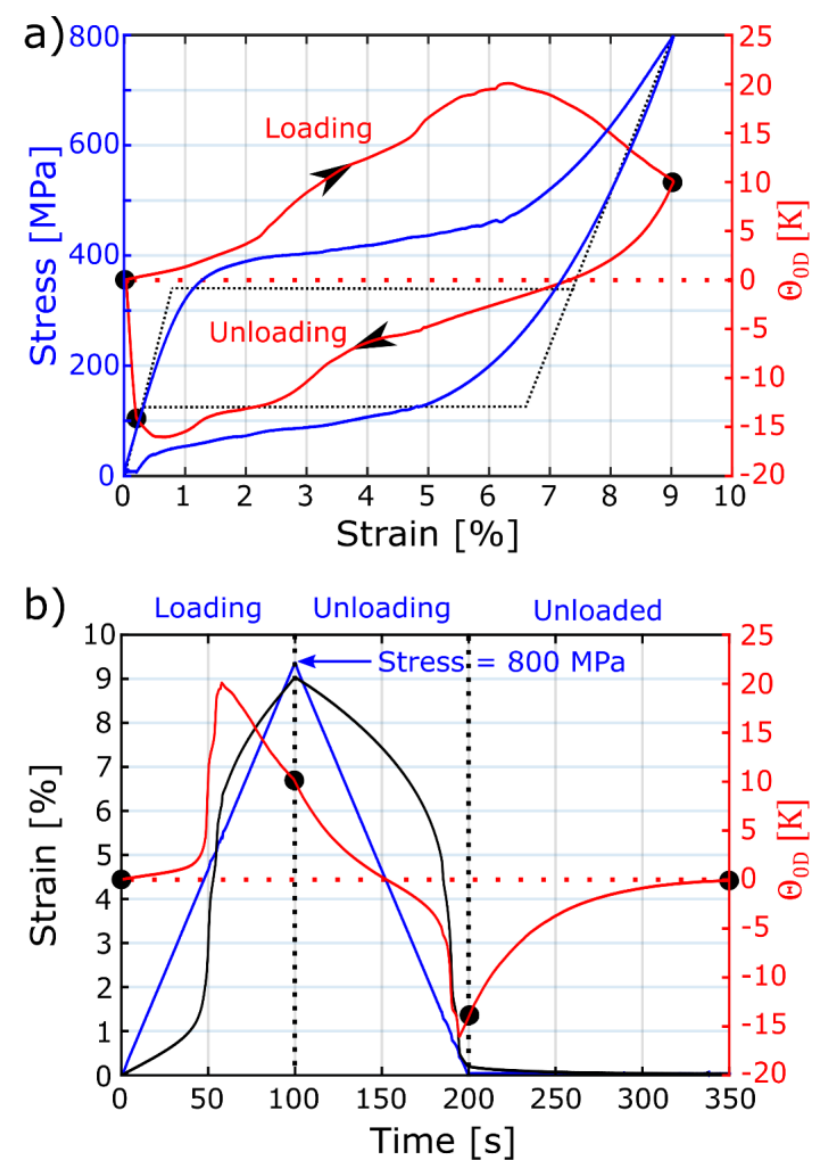

Fig. 5 Macroscopic response during the superelastic cycle: (a) temperature (averaged over the whole gage length of the wire) vs. engineering strain curve (red solid line), engineering stress vs. engineering strain curve (blue solid line), and scheme of isothermal superelastic response (black dashed line); (b) time evolutions. 

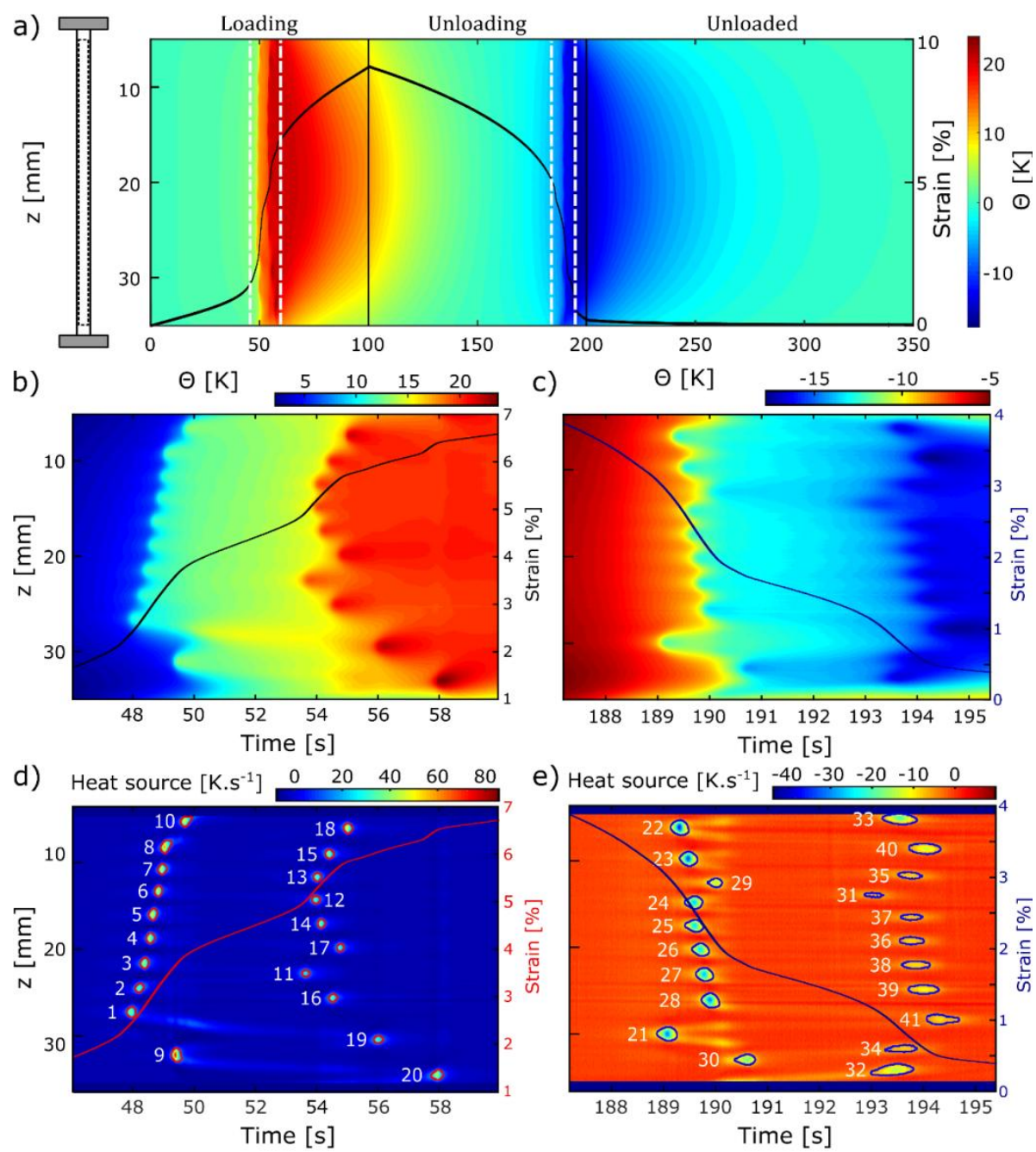

e) Heat source $\left[K . \mathrm{s}^{-1}\right] \quad-40 \quad-30 \quad-20 \quad-10 \quad 0$

f)

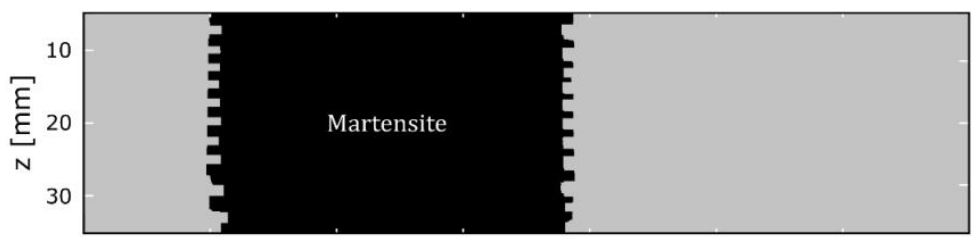

g)

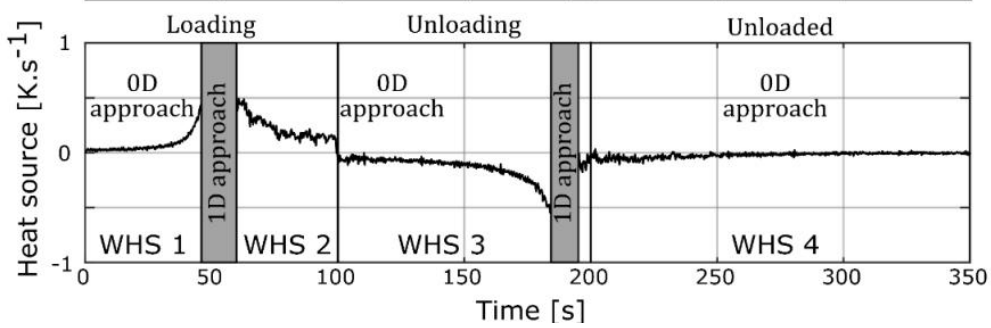

Fig. 6 Thermography and HSR during the superelastic cycle: (a) time evolution of thermographs represented by a color matrix where columns and rows represent times and wire axial direction respectively; $(b, c)$ details of the temperature color matrix delimited by the white vertical dashed lines, focusing on the time intervals of localized forward/reverse phase transformation, respectively; $(\mathrm{d}, \mathrm{e})$ heat sources reconstructed over the two selected time intervals; (f) binary color map of martensite phase distribution based on identified localized transformation events; (g) time evolution of weak heat sources (WHS) reconstructed in time intervals where no localized events appeared. 

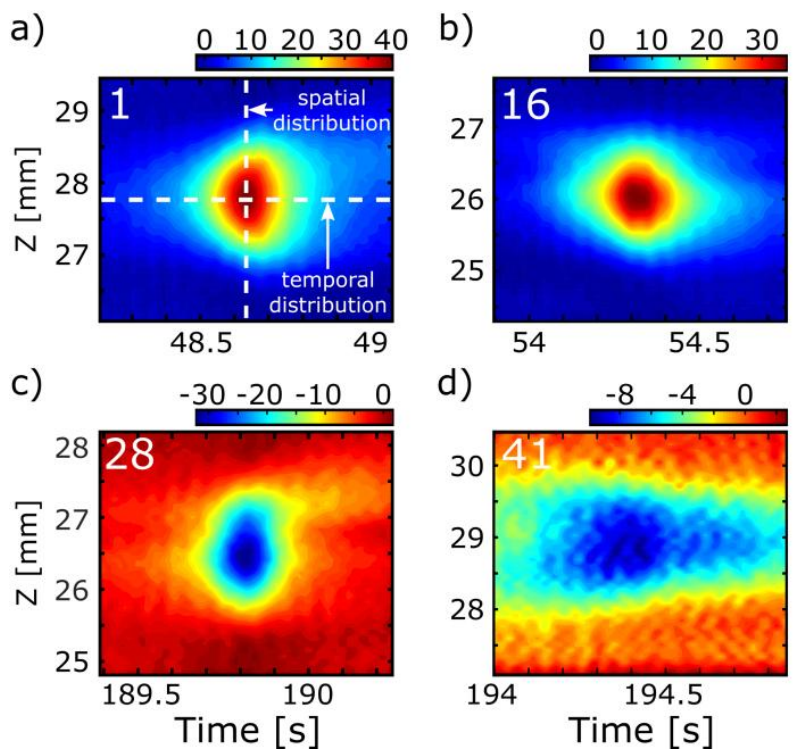

Fig. $7(a, b)$ Spatiotemporal color matrices of reconstructed localized heat sources related to martensite nucleation and merging events that appeared during loading at locations 1 and 16 as depicted in Fig. 6d, respectively; (c,d) same for austenite nucleation and merging events that appeared during unloading at locations 28 and 41 as depicted in Fig. 6e, respectively. 

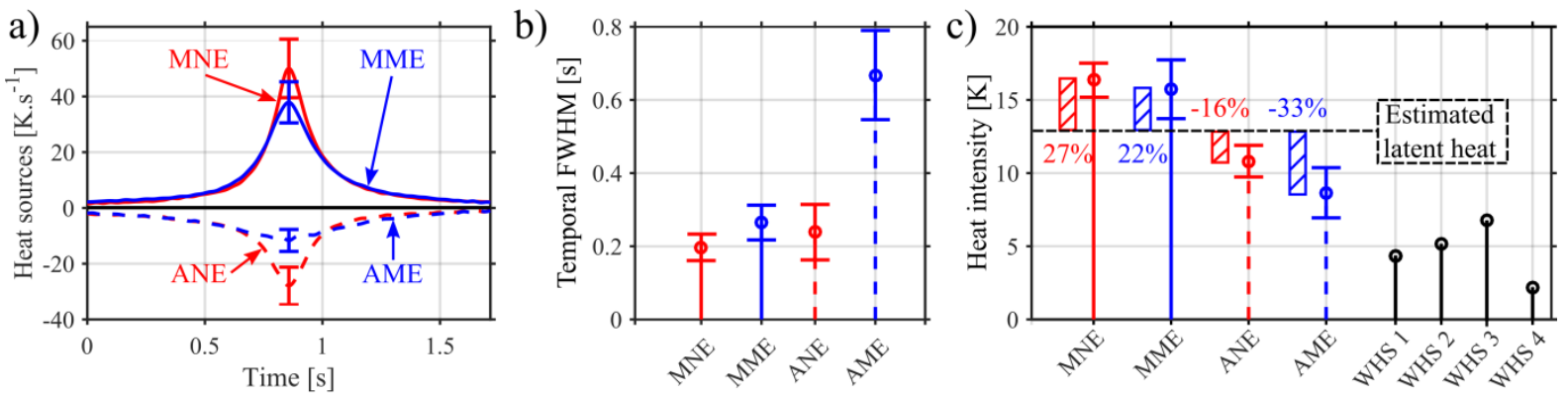

$\longrightarrow$ Martensite nucleation events $(\mathrm{MNE})$ - $\odot$ Austenite nucleation events (ANE) $\longrightarrow$ Weak heat source (WHS) $\rightarrow$ Martensite merging events (MME) - ๑ Austenite merging events (AME)

d)

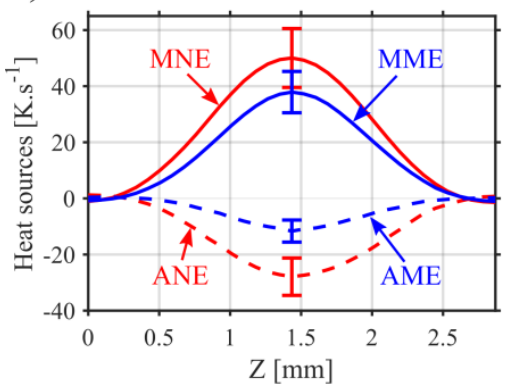

e)

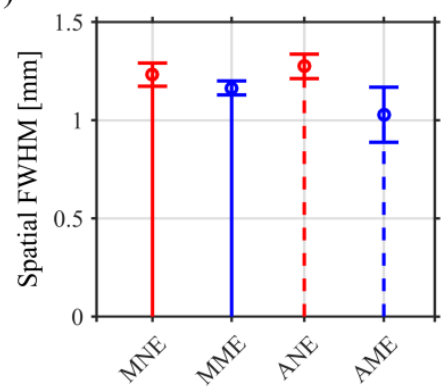

f)

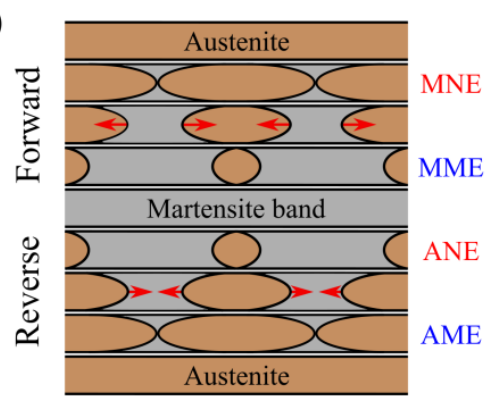

Fig. 8 (a,d) Averaged heat sources for each of the four types of localized events as a function of time and space, respectively. Standard deviations are also indicated at the maximum intensities; (b,e) temporal and spatial Full Widths at Half Maxima (FWHM) of the localized heat sources, respectively; (c) time integral distributions of the localized (from Fig. 8a) and weak heat sources (from Fig. $6 \mathrm{~g}$ ). The black dashed line represents the magnitude of the latent heat estimated as the average intensity. Hashed bars represent estimates of intrinsic dissipation; (f) scheme of the progress of the localized transformation in the wire in a form of nose cone-shaped martensite band fronts [35] appearing/propagating/disappearing during loading and unloading. Red arrows denote the direction of the front motion. 